\title{
Determination of fluorene in sea-water by room temperature phosphorescence in organised media $\dagger$
}

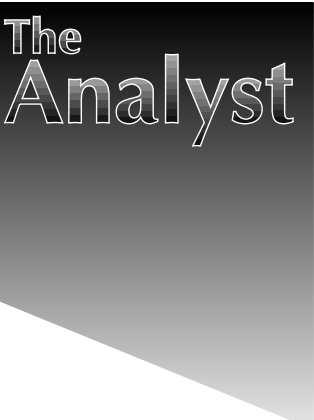

\author{
Manuel Algarra González and Miguel Hernández López* \\ Department of Analytical Chemistry, Faculty of Sciences, University of Málaga, Campus de \\ Teatinos s/n, 29071 Málaga, Spain. E-mail: sulphur@uma.es
}

\section{Received 4th June 1998, Accepted 18th August 1998}

Fluorene, insoluble in water, forms an inclusion compound in aqueous media with $\beta$-cyclodextrin, with an equilibrium constant of $2290 \pm 1501 \mathrm{~mol}^{-1}$ at $15^{\circ} \mathrm{C}$. The inclusion phenomenon was studied by fluorimetric and phosphorimetric techniques. A schematic host-guest model to explain the inclusion complex structure is reported. The phosphorescence spectra showed maximum excitation and emission wavelengths at 304 and $460 \mathrm{~nm}$, respectively. The phosphorescence lifetimes were calculated employing different organic and inorganic perturber atoms, and was $185 \mathrm{~ms}$ for 3-bromopropan-1-ol. Optimum conditions of the method were [ $\beta$-cyclodextrin] $=$ $8 \times 10^{-3} \mathrm{M}, \mathrm{pH}=6.65,3$-bromopropan-1-ol as heavy atom, sodium sulfite-sulfurous acid as oxygen scavenger, $\beta$-cyclodextrin, heavy atom and buffer as addition order, temperature $15^{\circ} \mathrm{C}$ and $t_{\mathrm{d}}$ and $t_{\mathrm{g}} 0.1$ and $13 \mathrm{~ms}$, respectively. The main figures of merit were linear dynamic range $15-2000 \mathrm{ng} \mathrm{ml}^{-1}$, detection limit $4.5 \mathrm{ng} \mathrm{ml}^{-1}$ and RSD 2.5\%. The method has a moderate selectivity against other PAHs and aromatic molecules and a considerable increase in selectivity in comparison with fluorimetric measurements is observed. An application of this technique to fluorene determination in environmental sea-water samples with successful results is described.

\section{Introduction}

Polycyclic aromatic hydrocarbons (PAHs) are a family of compounds which appear as complex mixtures in the environment. Owing to their ubiquity, the characterization, quantification and study of their properties are of great importance. ${ }^{1-4}$ The main sources of these compounds are anthropogenic pyrolytic and combustion processes related to industrial plants, domestic heating and automobile traffic; from these sources they enter aquatic biota, where they are rapidly taken up and accumulated by both fish and algae. They are particularly interesting because at least some of them have been found to be toxic and a number of epidemiological studies have shown that they can induce the development of certain forms of tumours. ${ }^{5}$

Fluorene, a three-ring diaromatic hydrocarbon, a precursor of other PAHs is a common component of crude and processed fossil fuels and it has been identified as a carcinogenic agent and an important component of hydrocarbon pollution of aquatic ecosystems, and it appears to be highly toxic to fish and algae. ${ }^{5-7}$ Its determination in sea-water has been achieved by gas chromatography (GC) with flame ionization detection (GCFID $)^{5}$ and mass spectrometry (GC-MS $)^{8}$ and liquid and micellar chromatography with fluorescence detection (LC-F). ${ }^{9,11}$ Lebo and Smith ${ }^{12}$ determined fluorene in fish tissues, plants and sediments. Luminescence spectroscopy is a particularly useful and powerful technique for this purpose because of its high sensitivity; 13 other studies have been based on work at low temperature using Shpol'skii spectroscopy with very low limits of detection. ${ }^{14,15}$

Because of the ability of cyclodextrins and their derivatives to form stable inclusion compounds with numerous species in aqueous media, ${ }^{16,17}$ they have been widely used as stabilizing and solubilizing systems and moreover to enhance the luminescence phenomena of molecules introduced into the hydrophobic internal cavity. Deoxygenation is a key step for observing phosphorescence and chemical deoxygenation employing so-

$\uparrow$ Presented at the VIIIth International Symposium on Luminescence Spectrometry in Biomedical and Environmental Analysis, Las Palmas de G.C., Spain, May 26-29, 1998. dium sulfite has been successfully used. ${ }^{18}$ Room temperature phosphorescence of fluorene has been observed by means of $\beta$ cyclodextrin $(\beta-C D)$ and micelles but only qualitative data have been reported. ${ }^{19-22}$ In this work, luminescent characteristics of the inclusion compound of fluorene in $\beta$-CD aqueous solution were studied with the object of characterizing the inclusion process involved and proposing a phosphorimetric method for its determination in sea-water. The procedure proposed compared favourably with the fluorimetric technique in terms of selectivity, good limit of detection, low RSD and a wide linear dynamic range.

\section{Experimental}

\section{Reagents}

$\beta$-Cyclodextrin ( $\beta$-CD) and $\alpha$-cyclodextrin (Sigma, St. Louis, MO, USA), $\gamma$-cyclodextrin (Fluka, Buchs, Switzerland), methyl- $\beta$-cyclodextrin, hydroxypropyl- $\alpha$-cyclodextrin, hydroxypropyl- $\beta$-cyclodextrin and hydroxypropyl- $\gamma$-cyclodextrin (Aldrich, Milwaukee, WI, USA) were used in aqueous solution $\left(10^{-2} \mathrm{M}\right)$ without further purification.

Stock standard solutions (2000 $\left.\mu \mathrm{g} \mathrm{ml}^{-1}\right)$ of fluorene, phenanthrene, anthracene, pyrene, chrysene, 1,2-benzanthracene, 1,2:5,6-benzanthracene, benzo[ $[a]$ pyrene, benzo $[e]$ pyrene, triphenylene, fluoranthene, acridine and carbazole (Aldrich), naphthalene, acenaphthene (Sigma), biphenyl, 1-naphthol, 2-naphthol (Merck, Darmstadt, Germany), 2-bromofluorene, dibenzothiophene, dibenzofuran and 9-bromofluorene (Acros, Geel, Belgium) were prepared in propan-1-ol (Merck). Organic heavy atoms used were 1,3-dichloropropan2-ol, 2,3-dichloropropan-1-ol, 2,2,2-trichloroethanol, 3-chloropropan-1-ol, 1,4-dibromobutane, dibromomethane, 3-bromopropan-1-ol, 1,3-dibromopropane, 1,2-dibromethane, 1-bromopropane, 2-bromoethanol, 2,3-dibromopropan-1-ol, 2-bromoethylammonium bromide, iodomethane, 2-iodopropane, diiodomethane, 1,2-diiodoethane, 1-iodopropane, all of 'for synthesis' grade from Merck; 1,3-dibromopropan-2-ol of 
'for synthesis' grade (Aldrich), bromoform, of analyticalreagent grade (Janssen, Geel, Belgium) and chloroform, of analytical-reagent grade (Merck). Heavy inorganic salts were potassium bromide, potassium iodide, mercury(II) bromide, mercury(II) nitrate monohydrate, mercury(II) iodide, silver nitrate, thallium(I) nitrate, lead(II) nitrate, all of analyticalreagent grade from Merck. In all cases, the final concentration of heavy atom was 0.15 M. Sodium sulfite $(2 \mathrm{M})$ and sulfurous acid (5-6\% $\left.\mathrm{SO}_{2}\right)$, purchased from Merck, were used for appropriate chemical deoxygenation. Methanol, ethanol, propan-1-ol, propan-2-ol, tert-butyl alcohol, isobutanol, butan1-ol, butan-2-ol, cyclohexanol, cyclopentanol, glycerine (Merck) and ethylene glycol monomethyl ether and pentan-1-ol (Sigma) were of analytical-reagent grade and were used without further purification. Other chemicals used were of analyticalreagent grade and all solutions were prepared with ultrapure water (obtained from a Milli-Q/Milli-Q2 system, Millipore, Bedford, MA, USA).

\section{Apparatus}

All excitation and emission temperature phosphorescence (RTP) spectra were obtained with a Perkin-Elmer (Norwalk, CT, USA) LS-5 luminescence spectrophotometer, equipped with a xenon pulsed discharge lamp $(9.9 \mathrm{~W})$ pulsed at line frequency $(10 \mu \mathrm{s}$ half-width, $50 \mathrm{~Hz})$ and an F/3 MonkGuilleson-type monochromator. The spectrometer was connected to a Perkin-Elmer Model 3600 data station microcomputer, provided with PECLS II applications software. The photomultiplier signal was measured with gated electronics. The delay time $\left(t_{\mathrm{d}}\right)$ and the gate time $\left(t_{\mathrm{g}}\right)$ chosen were 0.1 and $13.0 \mathrm{~ms}$, respectively, and the excitation and the emission slits were set to 5 and $10 \mathrm{~nm}$, respectively. The phosphorescence lifetimes were obtained by employing the Obey-Decay application program. A quartz cuvette $(10 \times 10 \mathrm{~mm})$ with PTFE stopper to avoid contact with air was used. In order to homogenize the turbid samples in the cuvette, a Model 333 magnetic stirrer (Hellma, Mulheim, Germany) was employed. The temperature was maintained at $15 \pm 0.5^{\circ} \mathrm{C}$ by an ultrathermostatic water-bath circulator (Frigiterm S-382, Selecta, Barcelona, Spain). A Bransom Model 5200 ultrasonic water-bath (Branson Ultrasonics Co., Danbury, CT, USA) was used to homogenize the samples.

\section{General procedures}

Study of inclusion phenomena. To aliquots of fluorene $\left(0.05 \mu \mathrm{g} \mathrm{ml}^{-1}\right)$ in acetone solution, gently heated in order to eliminate the solvent, were added increasing volumes of $0.01 \mathrm{M}$ $\beta$-CD solution and de-ionised water to give a final volume of 10 $\mathrm{ml}$. These samples were sonicated for $10 \mathrm{~min}$ and their fluorescence spectra, at different temperatures, were recorded with excitation at $261 \mathrm{~nm}$.

Phosphorimetric determination of fluorene. Into a $10 \mathrm{ml}$ calibrated flask were transferred aliquots of a sample containing $0.05-70 \mu \mathrm{g}$ of fluorene in propan-1-ol, propan-1-ol to a final volume of $50 \mu \mathrm{l}, 9 \mathrm{ml}$ of $0.01 \mathrm{M} \beta-\mathrm{CD}$ solution, $150 \mu \mathrm{l}$ of 3-bromo-1-propanol, $0.4 \mathrm{ml}$ of $2 \mathrm{M}$ sodium sulfite and $0.4 \mathrm{ml}$ of sulfurous acid. The samples were sonicated in an ice-bath for 5 min, left until they reached $15^{\circ} \mathrm{C}$ and then the phosphorescence intensity was measured at $461 \mathrm{~nm}$ with excitation at $304 \mathrm{~nm}$ against a reagent blank.

Determination of fluorene in sea-water. Aliquots of seawater samples were placed in a $10 \mathrm{ml}$ calibrated flask and $50 \mu \mathrm{l}$ of propan-1-ol, a mass of solid $\beta$-CD (final concentration 8.85 $\left.\times 10^{-3} \mathrm{M}\right), 150 \mu \mathrm{l}$ of 3-bromo-1-propanol, $0.4 \mathrm{ml}$ of sodium sulfite and $0.4 \mathrm{ml}$ of sulfurous acid were added. The phosphorescence was measured as described above.

\section{Results and discussion}

\section{Study of inclusion process}

Fluorene forms an inclusion complex with $\beta$-CD of stoichiometry $1: 1$ obtained by the continuous-variations method (Job plot) from absorbance and fluorescence measurements. The equilibrium constants for the complexation between fluorene and $\beta-\mathrm{CD}$ at $\mathrm{pH} 7.0$ and at different temperatures were calculated by the Benesi-Hildebrand method. ${ }^{23}$ The linear relationship between $\Delta F^{-1}$ and $[\beta-\mathrm{CD}]^{-1}$ gave $K$, and the thermodynamic parameters $\Delta H, \Delta S$ and $\Delta G^{\circ}$ for the formation inclusion complex were determined from the temperature dependence of the association constants. ${ }^{24}$ Inclusion constants were 2290, 757, 470 and $1661 \mathrm{~mol}^{-1}$ at 288, 293, 298 and 303 $\mathrm{K}$, respectively, and the thermodynamic parameters were $\Delta H=$ $-12.10 \mathrm{~kJ} \mathrm{~mol}^{-1}, \Delta S=0.35 \mathrm{~kJ} \mathrm{~mol}^{-1} \mathrm{~K}^{-1}$ and $\Delta G^{\circ}=$ $-116.40 \mathrm{~kJ} \mathrm{~mol}^{-1}$, so the inclusion process is governed by a positive entropy change; the process essentially involves a hydrophobic interaction and the fluorene molecule tends to be introduced into the internal cavity of the cyclodextrin to attain the maximum order. Moreover, molecular modelling system software (Hyperchem, from Hypercube, Waterloo, Canada) was used to minimize the energy of the inclusion process and so to optimize the geometry of the complex; to remove intentionally the guest from the internal cavity of the cyclodextrin and to minimize the system, this evolves as a structure of minimum energy (Fig. 1). Other cyclodextrins assayed, all at a concentration of $0.01 \mathrm{M}$ in aqueous solution, such as $\alpha$-cyclodextrin, hydroxypropyl- $\alpha$-cyclodextrin, methyl- $\beta$-cyclodextrin, hydroxypropyl- $\beta$-cyclodextrin, $\gamma$-cyclodextrin and hydroxypropyl- $\gamma$ cyclodextrin, showed slight changes in the intensity and maximum wavelength of the spectra recorded in their absence, smaller values of the inclusion constants being obtained.

\section{Phosphorimetric study}

Fluorene shows intense phosphorescence in $\beta$-CD solution with maximum excitation at 270 and $304 \mathrm{~nm}$ and emission maxima at 434 and $461 \mathrm{~nm}$ (Fig. 2). Negligible phosphorescence is given by a blank under identical conditions. In other cyclodextrins and derivatives assayed cited earlier phosphorescence emission was not observed, probably owing to a poor host-guest fit (of

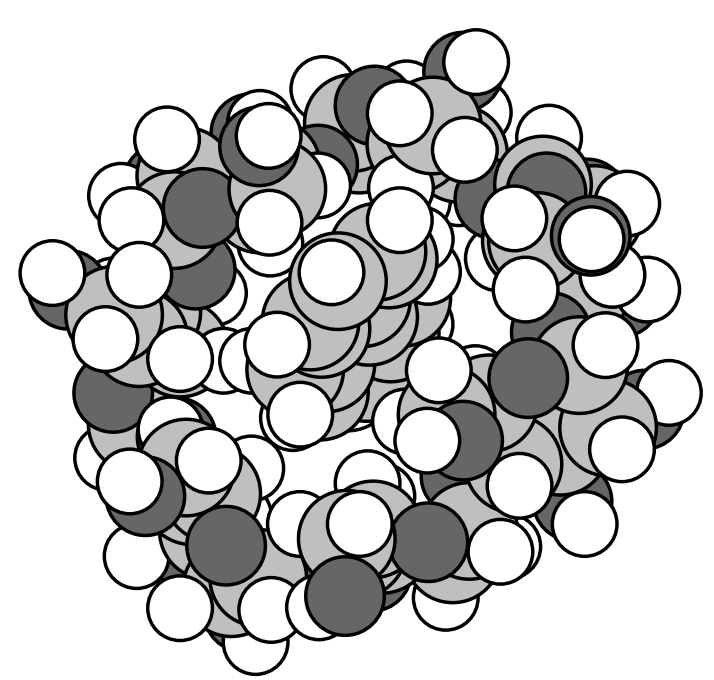

Fig. 1 Structure of $\beta$-cyclodextrin-fluorene complex. 
different size) or to steric hindrance of substituents. Other PAHs and aromatic molecules were studied under the same conditions as for fluorene and some spectral characteristics are given in Table 1.

Sample treatment. The previous immersion of the sample in an ice-bath and sonication for $5 \mathrm{~min}$ produced an immediate and intense emission in relation to the sample prepared at room temperature. In Fig. 3 it can be observed that the kinetics for the sample prepared at room temperature are slow, reaching equilibrium (curve 1) under these conditions at a time longer than $15 \mathrm{~min}$; similar results were obtained when samples were sonicated at room temperature for 5 or $10 \mathrm{~min}$ (curves 2 and 3). The sample introduced for $5 \mathrm{~min}$ in an ice-bath without sonication (curve 4) attained equilibrium after $5 \mathrm{~min}$, whereas for the sample sonicated for 5 or 10 min (curves 5 and 6) it was instantaneous. Subsequent work was carried out with sonication for $5 \mathrm{~min}$ in an ice-bath.

Influence of solvent, $\mathrm{pH}$ and oxygen scavenger. To avoid elimination of the solvent by heating the sample, the effects on the kinetics and phosphorescence signal in different solvents were studied. An aliquot of $50 \mu \mathrm{l}$ of each solvent was added to

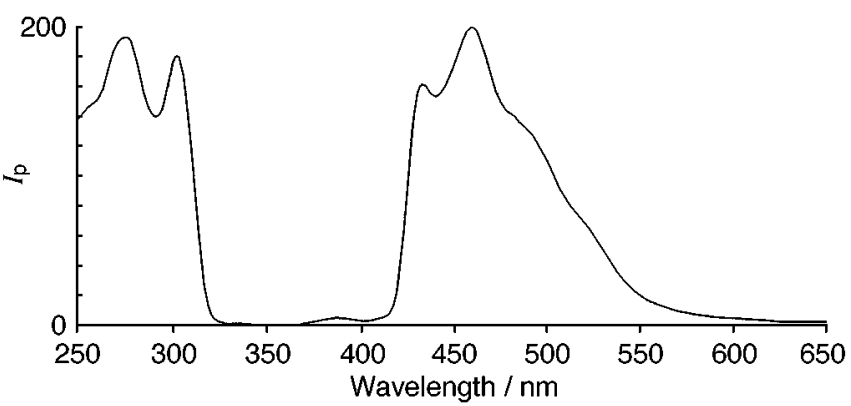

Fig. 2 Excitation and emission spectra of fluorene in $\beta$-cyclodextrin solution. [Fluorene] $=1 \mu \mathrm{g} \mathrm{ml}^{-1}$; [propan-1-ol] $=0.066 \mathrm{M} ;[\beta-\mathrm{CD}]=8.5$ $\times 10^{-3} \mathrm{M}$; [3-bromopropan-1-ol] $=0.17 \mathrm{M}$; [sodium sulfite $]=0.08 \mathrm{M}$; [sulfurous acid $]=0.032 \mathrm{M} ; \mathrm{pH}=6.65$.

Table 1 Phosphorescent spectral characteristics of some PAHs and aromatic molecules in $\beta$-cyclodextrin aqueous solution

\begin{tabular}{|c|c|c|}
\hline Species & $\lambda_{\mathrm{ex}} / \lambda_{\mathrm{em}} / \mathrm{nm}$ & $\begin{array}{l}\text { Relative } \\
\text { phosphorescence } \\
\text { intensity }\end{array}$ \\
\hline Acenaphthene & 293/482, 516 & 60 \\
\hline Anthracene & - & - \\
\hline Biphenyl & - & - \\
\hline 9-Bromofluorene & - & - \\
\hline Naphthalene & 290/474, 508 & 50 \\
\hline Benzo $[a]$ pyrene $^{a}$ & - & - \\
\hline Benzo $[e]$ pyrene $^{a}$ & - & - \\
\hline Pyrene $^{a}$ & $323,339 / 589$ & 15 \\
\hline Fluoranthene $^{a}$ & 一 & - \\
\hline Fluorene & $270,304 / 434,461$ & 195 \\
\hline 1-Naphthol & $300 / 491,521$ & 20 \\
\hline Benzo $[k]$ fluoranthene & $309 / 565$ & 17 \\
\hline 1,2:5,6-Benzanthracene & - & - \\
\hline 1,2-Benzanthracene & - & - \\
\hline Acridine & - & - \\
\hline Dibenzofuran & $292 / 417,443$ & 580 \\
\hline Dibenzothiophene & $289,323 / 420,445$ & 132 \\
\hline Carbazole & $295,320 / 416,441$ & 232 \\
\hline Phenazine & - & - \\
\hline Triphenylene & $300 / 433,461$ & 52 \\
\hline 2-Naphthol & $324 / 489,519$ & 12 \\
\hline 2-Bromofluorene & - & - \\
\hline Phenanthrene & 294/463, 497 & 152 \\
\hline Chrysene & $306 / 511$ & 17 \\
\hline
\end{tabular}

a final volume of $10 \mathrm{ml}$ and it was observed that short and nonlinear alcohols (methanol, ethanol, propan-2-ol, tert-butyl alcohol, isobutanol, butan-2-ol and glycerine) gave a smaller signal than longer and cyclic alcohols (propan-1-ol, butan-1-ol, pentan-1-ol, cyclopentanol and cyclohexanol). The best results were obtained with propan-1-ol; the other solvents gave similar signals with slow kinetics. Different concentrations of propan1-ol were studied to evaluate their influence on the kinetics and equilibrium of the inclusion process. Up to $6.6 \times 10^{-2} \mathrm{M}$ the emission was instantaneous and for higher concentrations an induction period $\left(t_{\mathrm{i}}\right)$ was observed (for $0.132 \mathrm{M}, t_{\mathrm{i}}=250 \mathrm{~s}$; for $0.396 \mathrm{M}, t_{\mathrm{i}}=600 \mathrm{~s}$ ) (Fig. 4). The molecule of fluorene can compete between the apolar cavity of $\beta-\mathrm{CD}$ and its affinity or solubility in propan-1-ol. An optimum concentration of $0.066 \mathrm{M}$ was chosen.

In order to study the influence of $\mathrm{pH}$ on phosphorescence, several mixtures with different ratios of $2 \mathrm{~m}$ sodium sulfite solution and sulfurous acid were employed. In the $\mathrm{pH}$ range 6.3-6.9, the complex developed maximum and constant phosphorescence (Fig. 5). A pH of 6.65 corresponding to a molar ratio of $1: 2.5$ (sulfurous acid : sodium sulfite) was chosen for subsequent work. Other buffers were studied (acetate-acetic acid, citrate-citric acid and phosphate), also adding sodium sulfite to obtain the same concentration as above. In these cases it was necessary to employ high concentrations of buffer to maintain the $\mathrm{pH}$ after the addition of sulfite; moreover, the kinetics were the slowest, requiring $20 \mathrm{~min}$ for equilibrium. This can be explained by the greater competition between buffer and cyclodextrin in relation to the analyte. On the other hand, this mixture acts as an oxygen scavenger; in the absence of sulfurous acid ( $\mathrm{pH}$ 9.2) a weak phosphorescence signal was observed and with increasing emission, as for sulfurous acid, with a sulfurous acid:sodium sulfite molar ratio range of $0.35-0.65$ equilibrium was obtained immediately and the signal was maximum and constant ( $\mathrm{pH}$ 6.3-6.9); at higher ratios the signal decreased drastically.

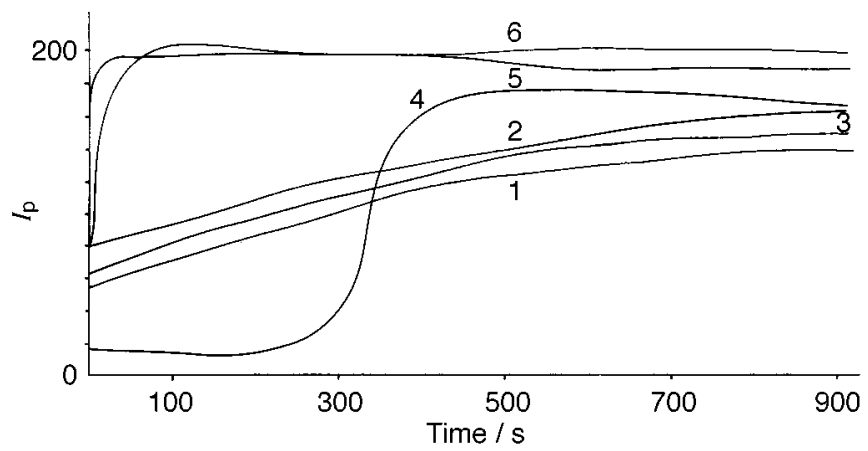

Fig. 3 Effect of temperature and sonication time on the phosphorescence emission: (1), (2) and (3) at room temperature with sonication for 0,5 and $10 \mathrm{~min}$, respectively; (4) in an ice-bath for $5 \mathrm{~min}$ without sonication; (5) and (6) in an ice-bath with sonication for 5 and $10 \mathrm{~min}$, respectively. [Fluorene] $=1 \mu \mathrm{g} \mathrm{ml}^{-1} ; \mathrm{pH}=6.65 ; \lambda_{\mathrm{em}}=461 \mathrm{~nm}$.

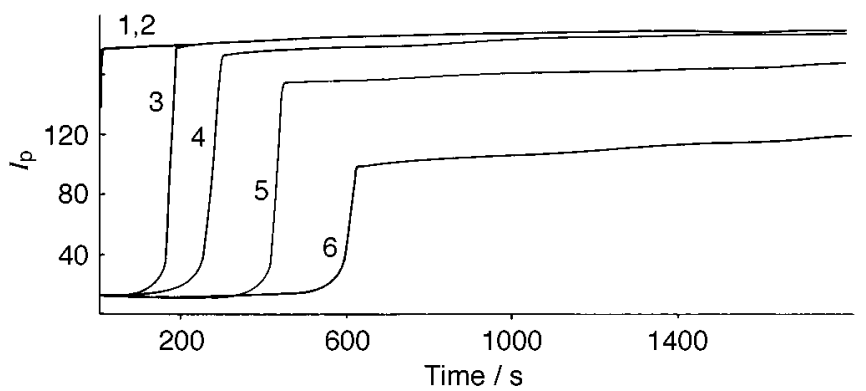

Fig. 4 Effect of the concentration of 1-propanol: (1), 0; (2) 0.066; (3) 0.099 ; (4) 0.132 ; (5) 0.264 ; and (6) $0.396 \mathrm{M}$. [Fluorene] $=1 \mu \mathrm{g} \mathrm{ml}^{-1} ; \mathrm{pH}$ $=6.65 ; \lambda_{\mathrm{em}}=461 \mathrm{~nm} ;[3$-bromopropan-1-ol $]=0.17 \mathrm{M}$. 
Influence of heavy atom. Different organic and inorganic molecules were studied as heavy atom perturbers. Mineral salts $\left[\mathrm{TlNO}_{3}, \mathrm{~Pb}\left(\mathrm{NO}_{3}\right)_{2}, \mathrm{Hg}\left(\mathrm{NO}_{3}\right)_{2}\right.$, etc.] do not produce emission phosphorescence. This was also observed with alkyl halides and halogenated aliphatic alcohols containing chlorine and iodine; only bromine derivatives of these compounds produced emission and intense phosphorescence was observed with 1,3-dibromopropane,1,3-dibromopropan-2-ol and 3-bromopropan1-ol. The results obtained are presented in Table 2, where the relative phosphorescence intensities are given. For the rest of the work 3-bromopropan-1-ol was chosen as its kinetics are faster than those for 1,3-dibromopropan-2-ol with similar intensity emission and lifetime, probably owing to steric hindrance of bromine atoms making the coupling less effective. The effect of the concentration of 3-bromopropan-1-ol on the kinetics of the formation of the $\beta$-CD-fluorene-heavy atom trimolecular complex and on the intensity of the phosphorescence signal at equilibrium were studied; a $0.17 \mathrm{~m}$ heavy atom concentration was optimum. It is important to note that 2- and 9-bromofluorene do not show phosphorescence emission, that is, the presence of the bromine atom in these molecules does not produce the expected internal heavy atom effect, and even on adding 3-bromopropan-1-ol, these compounds probably do not form inclusion complexes. The lifetimes were calculated by employing the Obey-Decay application program with delay times between 0.1 and 11 ms with 10 measurements and with a correlation of at least 0.99 considering a monoexponential decay ( $\tau$ for 3-bromopropan-1-ol is $185 \mathrm{~ms}$ ). A delay time of $0.1 \mathrm{~ms}$ and a gate time of $13 \mathrm{~ms}$ were chosen as giving the best signal-to-noise ratio.

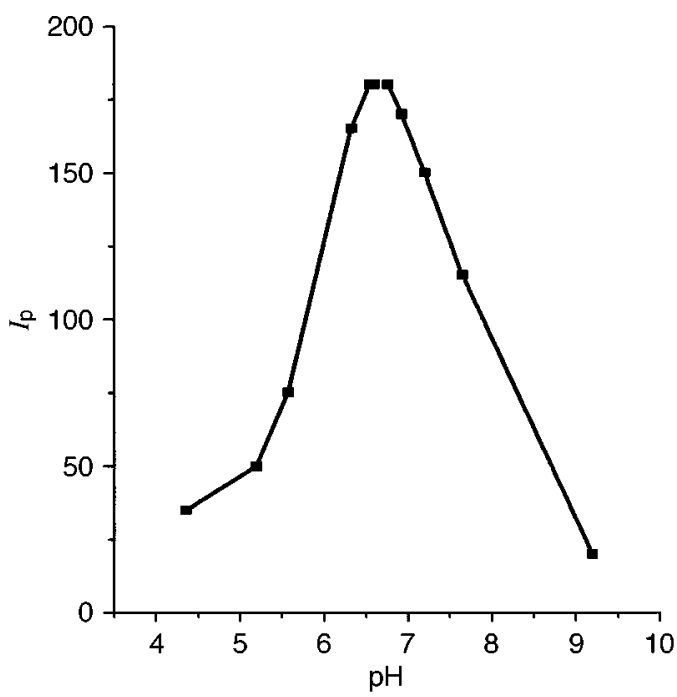

Fig. 5 Influence of $\mathrm{pH}$ on the phosphorescence intensity. [Fluorene] $=1$ $\mu \mathrm{g} \mathrm{ml}^{-1} ;[\beta-\mathrm{CD}]=8.85 \times 10^{-3} \mathrm{M} ; \mathrm{pH}=6.65 ; \lambda_{\mathrm{em}}=461 \mathrm{~nm}$.
Influence of cyclodextrin concentration, temperature and order of addition. The phosphorescence intensity increases and the time to attain equilibrium becomes shorter as the $\beta-C D$ concentration increases. In all subsequent experiments the $\beta$ $\mathrm{CD}$ concentration was maintained at $8.85 \times 10^{-3} \mathrm{M}$. A slight decrease in the phosphorescence intensity was observed in the interval $9-20{ }^{\circ} \mathrm{C}$ and a greater decrease above $25^{\circ} \mathrm{C}$. The work reported here was carried out at $15 \pm 0.5^{\circ} \mathrm{C}$. The order of addition is important and the sequence sample, $\beta-\mathrm{CD}$, heavy atom, sodium sulfite and sulfurous acid is recommended. The inclusion compound is stable for at least $1 \mathrm{~d}$.

\section{Figures of merit of the proposed method}

By employing the optimum values of the variables, a calibration graph obtained by the least-squares treatment was $I_{\mathrm{p}}=1.70+$ 1.35 [fluorene] with a correlation coefficient of 1.00 , and where $I_{\mathrm{p}}$ is the phosphorescence intensity and the concentration of fluorene is expressed in $\mathrm{n} \mathrm{ml}^{-1}$. The linear dynamic range was established between 15 and $7000 \mathrm{ng} \mathrm{ml}^{-1}$. The detection limit (4.5 $\mathrm{ng} \mathrm{ml}^{-1}$ ) was calculated as three times the standard deviation of seven blanks divided by the slope of the calibration graph. The precision was determined by analysing 10 samples containing $50 \mathrm{ng} \mathrm{ml}^{-1}$ of fluorene and it was $2.5 \%$ (as relative standard deviation).

\section{Interference study}

In order to evaluate the selectivity of the proposed method, the effect of various PAHs and molecules with similar structures on the phosphorimetric determination of fluorene at the $50 \mathrm{ng} \mathrm{ml}^{-1}$ level was examined over a wide range of concentrations. The tolerance criterion established was a deviation from the expected concentration of $\pm 3 s$, where $s$ is the standard deviation of the analytical signal for the procedure. The results are given in Table 3. The method tolerates a concentration ratio of $200: 1$ of biphenyl and moderate concentrations of naphthalene, acenaphthene, benzo $[a]$ pyrene, benzo[ $e]$ pyrene and anthracene. It is important to note the different tolerance ratios for 9- and 2-bromofluorene, probably due to steric hindrance for the bromine atom position in relation to the $\beta-\mathrm{CD}$ cavity. Rubio Barroso et al. ${ }^{25}$ determined, by spectrofluorimetry, several analytical parameters of fluorene included in $\beta-\mathrm{CD}$, such as linear dynamic range $\left(0.45-33.2 \mathrm{ng} \mathrm{m}^{-1}\right)$, RSD (2.6\%) and detection limit $\left(0.1 \mathrm{ng} \mathrm{ml}^{-1}\right)$. No interference study was reported in relation to the effect of other species on the fluorescence of fluorene. The fluorimetric measurements were made under the same conditions as for the phosphorimetric interference study but no heavy atom was added (Table 3 ). The great increase in selectivity in the phosphorimetric determination of fluorene in relation to the fluorimetric technique in some cases the increase in tolerance ratio is hundreds of times

Table 2 Influence of heavy atoms on the phosphorescence of fluorene

\begin{tabular}{|c|c|c|c|c|c|}
\hline Heavy atom ${ }^{a}$ & $I_{\mathrm{p}}$ & $\tau / \mathrm{ms}$ & Heavy atom ${ }^{a}$ & $I_{\mathrm{p}}$ & $\tau / \mathrm{ms}$ \\
\hline 1,3-Dichloropropan-2-ol & - & - & 2,3-Dibromopropan-1-ol & 2 & - \\
\hline 2,3-Dichloropropan-1-ol & - & - & Iodomethane & - & - \\
\hline 3-Chloropropan-1-ol & 37 & - & 2-Iodopropane & - & - \\
\hline 2,2,2-Trichloroethanol & - & - & Diiodomethane & - & - \\
\hline 1,4-Dibromobutane & 12 & 120 & 1,2-Diiodoethane & - & - \\
\hline Dibromomethane & - & - & 1-Iodopropane & - & - \\
\hline 1,3-Dibromopropane & 122 & 158 & 1,3-Dibromopropan-2-ol & 183 & 180 \\
\hline 1,2-Dibromethane & 40 & 164 & Bromoform & - & - \\
\hline 1-Bromopropane & 60 & 132 & Chloroform & 5 & - \\
\hline 2-Bromoethanol & 33 & 124 & 3-Bromopropan-1-ol & 180 & 185 \\
\hline
\end{tabular}


(naphthalene, 9-bromofluorene, acenaphthene, benzo[a]pyrene) \} is notable; this is due to the intrinsic nature and more restrictive conditions of the phosphorescence emission. Moreover, a synthetic coal tar (fluorene, benzo[ $a]$ pyrene, benzo[ $e]-$ pyrene, fluoranthene, pyrene and benzo[ $k]$ fluoranthene, all of them at a concentration of $50 \mathrm{ng} \mathrm{ml}^{-1}$ ) was analysed for fluorene and the relative error was $5 \%$.

\section{Application to sea-water samples}

The procedure was applied to determination of fluorene in natural and synthetic sea-water. The synthetic sea-water contained per litre the following salts: $0.12 \mathrm{~g}$ of $\mathrm{CaCO}_{3}, 1.75 \mathrm{~g}$ of $\mathrm{CaSO}_{4} \cdot \mathrm{H}_{2} \mathrm{O}, 29.7 \mathrm{~g}$ of $\mathrm{NaCl}, 2.48 \mathrm{~g}$ of $\mathrm{MgSO}_{4}, 3.32 \mathrm{~g}$ of $\mathrm{MgCl}_{2}, 0.55 \mathrm{~g}$ of $\mathrm{NaBr}$ and $0.53 \mathrm{~g}$ of $\mathrm{KCl}$. Sea-water samples were collected at different locations in the bay of Malaga (southern Spain). The samples, without filtration (the turbidity does not affect the phosphorescence emission), were spiked with fluorene and their phosphorescence intensities measured as described. Table 4 summarises the results; the good results

Table 3 Tolerable limits of foreign species (fluorene taken, 50 ng $\mathrm{ml}^{-1}$ )

\begin{tabular}{lll}
\hline & \multicolumn{2}{c}{$\begin{array}{l}\text { Tolerance ratio } \\
\text { (species to fluorene, } \mathrm{m} / \mathrm{m} \text { ) }\end{array}$} \\
\cline { 2 - 3 } Species added & Phosphorescence & Fluorescence \\
\hline Biphenyl & 200 & 5 \\
9-Bromofluorene & 100 & 0.1 \\
Naphthalene, acenaphthene & 40 & $0.05,0.1$ \\
Anthracene, benzo[ $a$ ]pyrene, & & \\
$\quad$ benzo[e]pyrene & 20 & $0.5,0.2,0.5$ \\
Pyrene & 4 & 1 \\
Fluoranthene, 1-naphthol & 2 & $0.1,0.1$ \\
Benzo[ $k$ ]fluoranthene & 2 & 1 \\
1,2:5,6-Benzanthracene, & & $0.5,1$ \\
$\quad$ 1,2-benzanthracene & 2 & $0.02,0.02$, \\
Acridine, dibenzofuran, & 1 & 0.02 \\
$\quad$ dibenzothiophene & & $0.5,0.2,0.2$ \\
Carbazole, phenazine, triphenylene & 1 & $0.1,0.1$ \\
2-Naphthol, 2-bromofluorene & 1 & 0.1 \\
Phenanthrene, chrysene & 0.5 & \\
\hline
\end{tabular}

Table 4 Determination of fluorene in sea-water

\begin{tabular}{|c|c|c|}
\hline Sea-water sample & $\begin{array}{l}\text { Fluorene added/ } \\
\mathrm{ng} \mathrm{ml}^{-1}\end{array}$ & $\begin{array}{l}\text { Fluorene found } \pm \\
\mathrm{ng} \mathrm{ml}^{-1}\end{array}$ \\
\hline Synthetic ${ }^{a}$ & 50 & $49 \pm 1.5$ \\
\hline Sacaba beach $^{b}$ & 50 & $51 \pm 2.1$ \\
\hline Harbour $^{b}$ & 50 & $52 \pm 3.0$ \\
\hline Malagueta beach ${ }^{b}$ & 50 & $50 \pm 1.5$ \\
\hline El Candado beach ${ }^{b}$ & 50 & $51 \pm 1.9$ \\
\hline Rincon de la Victoria beach ${ }^{b}$ & 50 & $52 \pm 2.2$ \\
\hline
\end{tabular}

obtained for the phosphorimetric determination of fluorene in sea-water demonstrate its applicability for routine analysis.

\section{Acknowledgements}

We thank the Consejeria de Educación y Ciencia de la Junta de Andalucia (Group FQM 0148) for supporting this study and Professors F. J. Lopez Herrera and S. Pino Gonzalez for designing the molecular model for the host-guest system studied.

\section{References}

1 J. M. Neff, Polycyclic Aromatic Hydrocarbons in the Aquatic Environment: Sources, Fate and Biological Effects, Applied Science, London, 1979.

2 M. L. Lee, M. V. Novotny and K. D. Bartle, Analytical Chemistry of Polycyclic Aromatic Compounds, Academic Press, London, 1981.

3 A. Bjorseth, Handbook of Polycyclic Aromatic Hydrocarbons, Marcel Dekker, New York, 1983.

4 C. Y. Raoux and P. Garrigues, in Organic Geochemistry: Advances and Applications in the Natural Environment; 15th Meeting of the European Association of Organic Geochemists, ed. D. A. C. Manning, Manchester University Press, Manchester, 1991, pp. 552.

5 P. A. Cerutti, Science, 1985, 227, 375.

6 D. L. Vassilaros, P. W. Stoker, G. M. Booth and M. L. Lee, Anal. Chem., 1982, 54, 106.

7 P. Thomas, H. W. Wofford and J. M. Neff, Aquat. Toxicol., 1981, 1, 329.

8 Y. Hsieh, M. B. Thompson and C. H. Ward, Dev. Ind. Microbiol., 1980, 2, 401

9 G. Green, J. H. Skerrat, R. Leeming and P. D. Nichols, Mar. Pollut. Bull., 1992, 25, 293.

10 S. A. Wise, M. M. Schantz, B. A. Benner, M. J. Hays and M. J. Schiller, Anal. Chem., 1995, 67, 1171.

11 S. Lopez, S. Rubio and L. M. Polo, J. Liq. Chromatog., 1995, 18, 2397.

12 J. A. Lebo and L. M. Smith, J. Assoc. Off. Anal. Chem., 1986, 69, 944.

13 M. Blanco, V. Cerdá, J. Coello, J. Gene, H. Iturriaga, S. Maspoch and M. T. Oms, Anal. Lett., 1996, 29, 1603.

14 C. Gooijer, I. Kozin and N. H. Velthorst, Mikrochim. Acta, 1997, 127, 149.

15 P. Garrigues and M. Ewald, Chemosphere, 1987, 16, 485.

16 D. Duchene, Cyclodextrins and Their Industrial Uses, Editions de Santé, Paris 1987.

17 K. A. Connors, Chem. Rev., 1997, 97, 1325.

18 M. E. Diaz Garcia and A. Sanz Medel, Anal. Chem., 1986, 58, 1436.

19 S. Scypinski and L. J. Cline-Love, Anal. Chem., 1984, 56, 322.

20 Y. Wei, W. J. Jin, R. H. Zhu, G. W. Xing, C. S. Liu, S. S. Zhang and B. L. Zhou, Spectrochim. Acta, Part A, 1996, 52, 683.

21 V. B. Nazarov, V. I. Gerko and M. V. Alfimov, Russ. Chem. Bull., 1996, 45, 2109.

22 W. Jin and C. S. Liu, Anal. Chem., 1993, 65, 863.

23 H. Benesi and J. Hildebrand, J. Am. Chem. Soc., 1949, 71, 2703.

24 F. García Sánchez, M. Hernández López and J. C. Márquez, J. Inclus. Phenom., 1990, 8, 389.

25 S. Rubio Barroso, López López, C. Val Ontillera and L. Polo Díez, Quím. Anal., 1991, 10, 127. 